\title{
A 3D progressive damage model for fatigue analysis of woven fabric composites
}

\author{
D.C. Pham, Jim Lua \\ Global Engineering and Materials, Inc. \\ 1 Airport Place, Princeton, NJ 08540
}

\begin{abstract}
A new 3D damage model is developed to predict the progressive failure and accumulated fatigue damage of woven fabric composite materials. Stress-based failure criteria are used to predict the damage initiation in $\mathrm{x}$-tow, $\mathrm{y}$-tow, and matrix constituent. An S-N based damage accumulation model is implemented to characterize the cycle dependent strength of the $x$ and $y$ - fiber tows and matrix subjected to axial tension, compression, or in-plane share loading. A curve-fit non-linear shear model is also employed based on the static coupon test data of $(+45 /-45)$ woven fabric laminates. A static failure progression module is used to predict the damage and failure at the peak load prior to fatigue cycling. Stiffness degradation, fatigue damage accumulation, and failure mode detection are performed during the fatigue marching process. The developed user-defined material model for Abaqus features: 1) description of initial nonlinear shear before the damage initiation; 2) characterization of failure initiation based on a maximum stress criterion; and 3) performance of fatigue damage accumulation using a phenomenological model based on S-N test data. The predictive capabilities of the developed model are demonstrated using tensiontension fatigue of SYNCOGLAS R420 E-glass woven fabrics.
\end{abstract}

\section{Introduction}

$\mathrm{W}^{\mathrm{on}}$ OVEN fabric materials have gained accelerated use in aerospace and marine industries due to their enhanced impact resistance, higher out-of-plane strength, easier construction of thick laminates with woven fabric. A macro-crack can be presented from defects during manufacturing process, impact or at a location of stress concentration. There is a need to accurately predict the fatigue behavior of woven fabrics of an arbitrary layup based on the test data of coupons with pre-defined ply orientations. While many studies have been performed on failure analyses of fiber-reinforced woven fabrics subject to quasi-static and dynamic load cases [1-8], progressive damage studies of the fabric materials due to fatigue are still limited because of the perception of a higher fatigue damage resistance of woven-fabric laminates under normal operating conditions. The presence of fabrication induced defects and the combined aggressive mechanical and environmental loading conditions has driven the current design and certification of a composite structure to be based on the damage tolerance approach. Predictive capability of fatigue damage and life prediction has played a key role for the successive implementation of the damage tolerance design and certification practice. Most importantly, a prediction tool has to be based on the physical properties that can be measured from key coupon level tests of pre-defined layups, loading directions, and applied stress ratios and peak load.

Conventional fatigue models of composite materials are based on the S-N approach using static stress components at hot spots without performing fatigue damage progression. Although a high fidelity stress distribution and the associated stress concentration can be identified, the use of a single point stress for the life prediction can be conservative which may result in less weight saving benefit by using a composite material. In order to remove this conservative approach associated with the service life prediction based on the first ply failure or on critical element basis, a progressive fatigue damage model has to be applied to allow the damage initiation, local material softening, stress re-distribution, damage progression, and the ultimate life prediction due to the rapid stiffness drop at the structural level. Currently, the S-N based phenomenological model has been used widely despite the issue associated with the use of S-N test data from un-notched specimens for fatigue life prediction of a component with initial 
defects or stress concentrations. This is mainly due to the low cost in generation of S-N fatigue data and quick failure prediction without invoking the extraction of crack growth driving force along its evolving front.

Nikishkov et al. [9] have introduced progressive simulation methods for unidirectional IM7/8552 composites, describing modeling methodologies to simulate the delamination, matrix damage onset and progression under fatigue loads. Similar fatigue damage studies using a phenomenological approach can be found in References [1011] based on progressive fatigue damage accumulation. Unlike a continuum damage modeling approach, a fracture mechanics based approach has been actively explored in the past years for the fatigue crack growth life prediction of unidirectional composites. A unified S-N based fatigue initiation and a Paris-law crack growth model has been developed by Cui et al. [12] to allow fatigue modeling of both matrix cracking and delamination. Xiao et al. [13] performed multiscale fatigue damage predictions for notched composites via a combined continuum and discrete crack modeling. A coupled r-XFEM with a cycle dependent cohesive model has been developed by Hoors et al. [14]. May and Hallett [15, 16] developed a combined model for damage initiation and propagation under fatigue loading using cohesive elements allowing modeling of the whole fatigue life in a single, coherent analysis.

In comparison with the UD composite, fatigue damage prediction for woven fabric composites is still in its formative stage with a great deal to be accomplished. Since matrix damage in the UD composite has been observed under fatigue loading, such a damage mode has to be incorporated for the fatigue damage characterization of the tow which is a unidirectional composite itself. Current approaches on fatigue modeling of woven fabrics are performed at a multiscale level including analyses of a representative volume element (RVE) model of the fiber bundles surrounded in a resin medium and prediction of its effective properties of RVEs for the ply level damage prediction $[17,18]$. These multiscale approaches require a number of simulations to calibrate constituent properties by matching the ply-level responses with testing results. The resulting analysis matrix can be large in order to characterize fatigue properties at different applied ratios and mode mixities. For fatigue damage assessment of a large structure, a homogenization approach needs to be utilized to determine the element stiffness at a given number of cycles from its constituent properties via a micromechanics model. Such a multiscale approach can be computationally intensive during the cyclic loading.

In this work, we present a new 3D damage model to evaluate progressive damage and fatigue life of balanced plain weave woven fabric materials at ply level based on the S-N coupon test data of [90/0] and [+45/-45] layups. Separate fatigue failure mode parameters in the warp and weft tows and in-plane matrix shearing of the fabrics are extracted from the corresponding coupon level S-N test data. The pre-peak static response is captured using an orthotropic elastic material model for both the X- and Y- tow while a nonlinear material model is used for the characterization of the in-plane shear. Damage initiation associated with X-tow, Y-tow, and in plane shear is detected using the maximum stress criteria with the cycle-dependent strength properties. The fabric stiffness matrix upon fatigue damage is degraded accordingly and the stress and strain fields are updated after a given increment number of cycles. A summary of modeling approach is described first, followed by its application for uniaxial fatigue tension specimens of R420 E-glass plain weave fabrics from Pandita et al. [19].

\section{Overview of CDM based fatigue model for woven fabric composites}

Woven fabric composite materials experience a nonlinear shear before reaching their peak load. A nonlinear shear stress-strain response of the matrix can be expressed as:

$$
\sigma_{12}^{m}=\sigma_{y}^{m}-\frac{K_{1}}{K_{2}}\left(e^{-K_{2} \varepsilon_{12}^{m}}-e^{-K_{2} \frac{\sigma_{y}^{m}}{G_{12}}}\right)
$$

where $\sigma_{12}^{m}, \varepsilon_{12}^{m}$ is the matrix plastic stress and plastic strain, $\sigma_{y}^{m}$ is the yielding strength of the matrix material, $G_{12}$ is the in-plane shear modulus, and $K_{1}$ and $K_{2}$ are the calibrated parameters determined from the nonlinear shear test of $(+45 /-45)$ woven fabric composite coupons.

The damage initiation can be either due to the load application before cycling or during the cycling at a given load level. The damage initiation in the X-tow (or 1-direction), Y-tow (or 2-direction) and the resin medium are detected by the maximum stress failure criteria, namely, 


$$
\begin{aligned}
& \left|\sigma_{12}\right| \geq S_{12} \\
& \left\{\begin{array}{l}
\sigma_{11 T} \geq S_{11 T} \\
\left|\sigma_{11 C}\right| \geq S_{11 C}
\end{array}\right. \\
& \left\{\begin{array}{l}
\sigma_{22 T} \geq S_{22 T} \\
\left|\sigma_{22 C}\right| \geq S_{22 C}
\end{array}\right.
\end{aligned}
$$

In the above equations $\sigma_{12}, \sigma_{11}, \sigma_{22}$ are the computed shear stress and longitudinal stresses along the $\mathrm{X}$ and $\mathrm{Y}$ tows directions; $S_{11 T}, S_{11 C}, S_{22 T}, S_{22 C}$ are the corresponding ultimate tensile and compressive strengths in the tows and $S_{12}$ is the in-plane shear strength of the fabric. These mechanical strengths are cycle-dependent.

A set of material S-N curves for the $(0,90)$ and $(45 /-45)$ woven fabric materials can be generated from experiment such as in [19]. Based on the measured S-N curves, curve-fit models are used to determine the cycledependent static strength parameters given by:

$$
\begin{aligned}
& \left.S_{11, \text { fatigue }}\right|_{\text {Tens/Comp }}=\left.S_{11, \text { static }}\right|_{T / C} \alpha_{1 T / C}\left(\log N_{11}\right)^{-\beta_{1 T / C}} \\
& \left.S_{22, \text { fatigue }}\right|_{\text {Tens/Comp }}=\left.S_{22, \text { static }}\right|_{T / C} \alpha_{2 T / C}\left(\log N_{22}\right)^{-\beta_{2 T / C}} \\
& \left.S_{12, \text { fatigue }}\right|_{\text {Tens/Comp }}=\left.S_{12, \text { static }}\right|_{T / C} \alpha_{12 T / C}\left(\log N_{12}\right)^{-\beta_{12 T / C}}
\end{aligned}
$$

with $\left.S_{i j, \text { static }}\right|_{T / C}(i j=11,22,12)$ referred to as the virgin tensile/compression fabric strengths in the 1-direction fiber tow, 2-direction fiber tow and in-plane shear strengths; $\left.S_{\mathrm{ij}, \text { fatigue }}\right|_{\text {Tens/Comp }}(i j=11,22,12)$ as the degraded strengths at increasing loading cycles; and $N_{i j}(i j=11,22,12)$ are the accumulative fatigue cycles.

Fatigue failure initiation for the woven fabric composites in the principal material directions can then be defined by failure indices $(F I)$ such as:

$$
\begin{aligned}
& F I_{11}=\frac{\sigma_{11}}{S_{11, \text { static }} \alpha_{1}\left(\log N_{11}\right)^{-\beta_{1}}} \leq 1 \\
& F I_{22}=\frac{\sigma_{22}}{S_{22, \text { static }} \alpha_{2}\left(\log N_{22}\right)^{-\beta_{2}}} \leq 1 \\
& F I_{12}=\frac{\sigma_{12}}{S_{12, \text { static }} \alpha_{12}\left(\log N_{12}\right)^{-\beta_{12}}} \leq 1
\end{aligned}
$$

where $\alpha_{1}, \beta_{1}, \alpha_{2}, \beta_{2}, \alpha_{12}, \beta_{12}$ are the calibrated parameters from the material S-N curves of the [90/0] and [45/-45] coupon tests and $F I_{11}, F I_{22}, F I_{12}$ are the fatigue failure indices in the longitudinal tow, transverse tow and the matrix of the fabric material.

The numbers of cycles to fatigue $N_{i j}$ for each element are calculated via a Newton iteration method as shown in Eq. 11 and updated after each increment of loading cycles, namely 


$$
\left\{\begin{array}{l}
F_{i j}=\frac{\sigma_{i j}}{S_{i j, s t a t i c} \alpha_{i j}\left(\log N_{i j}\right)^{-\beta_{i j}}}-1 \\
N_{i j}^{n+1}=N_{i j}^{n}-\frac{F_{i j}\left(N_{i j}\right)}{\partial F_{i j}\left(N_{i j}\right)} \\
N=N_{i j}^{n}(i j=11,22,12) \quad: \quad F_{i j}\left(N_{i j}\right)=0
\end{array}\right.
$$

Fatigue damage state variables $d_{F 11}, d_{F 22}, d_{F 12}$ are introduced to account for the accumulated fatigue damage in the tows and the matrix based on the Miner rule [21]. The damage variables range from 0 for no fatigue damage to unit for the complete fatigue failure. The residual fatigue life associated with respective matrix and fiber-dominated failure modes is then computed based on the number of fatigue cycle $N_{i j}$ experienced by each element and the computed damage variables $d_{F i j}$ as in Eqs. 12-14:

$$
\begin{aligned}
& \left\{\begin{array}{l}
d_{F 11}=\sum_{1}\left(\frac{\Delta n_{f}}{N_{11}}\right)<1 \\
N_{r 11}=\left(1-d_{F 11}\right) N_{11}
\end{array}\right. \\
& \left\{\begin{array}{l}
d_{F 22}=\sum_{1}\left(\frac{\Delta n_{f}}{N_{22}}\right)<1 \\
N_{r 22}=\left(1-d_{F 22}\right) N_{22}
\end{array}\right. \\
& \left\{\begin{array}{l}
d_{F 12}=\sum_{1}\left(\frac{\Delta n_{f}}{N_{12}}\right)<1 \\
N_{r 12}=\left(1-d_{F 12}\right) N_{12}
\end{array}\right.
\end{aligned}
$$

where $N_{i j}, N_{r i j}(i j=11,22,12)$ are the element fatigue cycles and residual fatigue cycles after damage. The material properties will be degraded dependent on the activated fatigue failure modes. The resulting material stiffness [C] will be updated to reflect the damage induced material softening.

When matrix shear failure is predicted, it is proposed to degrade the three shear moduli of the fabric material (Eq. 15) whereas a complete degradation of fabric properties is assumed once failure in the tows is activated (Eqs. 15-16):

$$
\begin{aligned}
& G_{i j}=\left(1-d_{F 12}\right)\left(1-d_{F 11}\right)\left(1-d_{F 22}\right) G_{i j 0} \quad(i j=12,13,23) \\
& E_{i}=\left(1-d_{F 11}\right)\left(1-d_{F 22}\right) E_{i 0} \quad(i=11,22,33)
\end{aligned}
$$

An iterative solution process is performed for the stress redistribution to achieve a new equilibrium state with updated material properties and stress states. New cycles to failure for each element is re-computed and an incremental number of cycles $(\Delta \mathrm{N})$ will be determined after ranking the number of cycles to failure for each element. The $\Delta \mathrm{N}$ is selected based on the user-provided number of elements to be failed at each solution stage to balance the solution accuracy and numerical efficiency. A flowchart for the progressive fatigue solution process based on the S-N approach is shown in Fig.1. The proposed fatigue model has been implemented as a user-material subroutine (UMAT) in Abaqus to estimate the fatigue damage accumulation. 


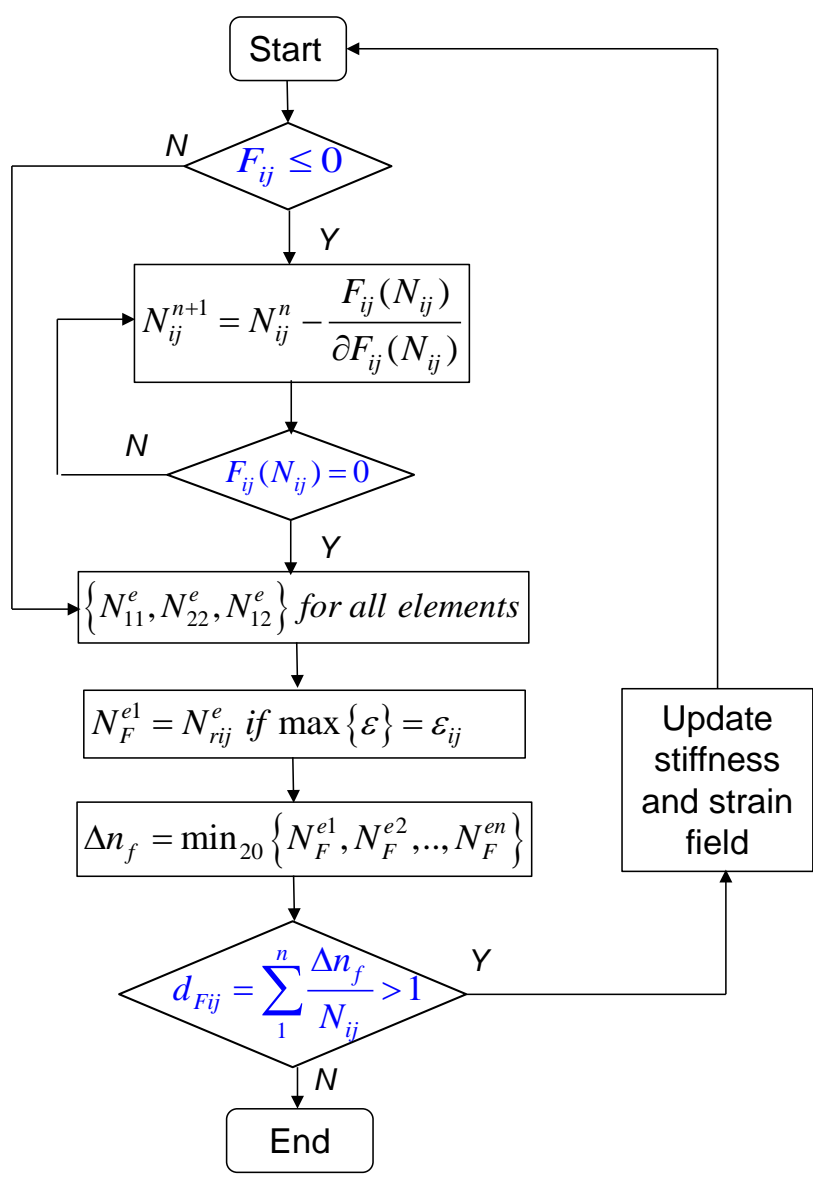

Figure 1. CDM based fatigue damage accumulation process for woven fabric composites.

\section{Extraction of model properties and fatigue failure prediction}

Pandita et al. [19] conducted tension static and fatigue tests of Eglass plain weave R420 fabric coupons. The fatigue specimens have dimensions of $230 \mathrm{~mm}$ x $25 \mathrm{~mm}$ x $2 \mathrm{~mm}$. The static tensile properties for different fabric layups are reported in Table 1 and the stress-strain responses for these layups are shown in Fig. 2. Fatigue tests were then conducted at different stress levels for the same coupon material for each layup. The S-N data of the fabrics of various stacking sequences are shown in Fig. 3 [19]. The testing results of (90/0) specimens indicate that the ultimate failure of the coupons is dominated by the failure of longitudinal yarns whereas the results of the (45/-45) coupons reveal extensive matrix cracks running at 45 degrees before fiber failure takes place.

Table 1. Static coupon testing results [19]

\begin{tabular}{lccc}
\hline Properties & Warp/Weft & Bias/45 & 30/60 \\
\hline Young's Modulus $\mathrm{E}_{\mathrm{x}}(\mathrm{GPa})$ & $20.5 \pm 0.5$ & $9.6 \pm 0.1$ & $11.1 \pm 0.2$ \\
Tensile Strength $\sigma_{\text {ult }}(\mathrm{GPa})$ & $410 \pm 13$ & $172.3 \pm 3.3$ & $197 \pm 4$ \\
Strain to failure (\%) & $2.1 \pm 0.1$ & $20.6 \pm 0.5$ & $11.3 \pm 0.6$ \\
\hline
\end{tabular}

Given the data summarized in Table 1, we used the coupon test data for the (90/0) and (+45/-45) layup for extraction of model parameters used in our strength degradation models shown in Eqs. 5-7. In addition, the model parameters for the nonlinear shear (Eq. 1) were determined from the curve fit of the static shear test data of $(+45 /-45)$. After 
determination of all the model parameters, a verification study was performed by comparing our model prediction with the test dada for the remaining coupon specimen of layup of (30/60).

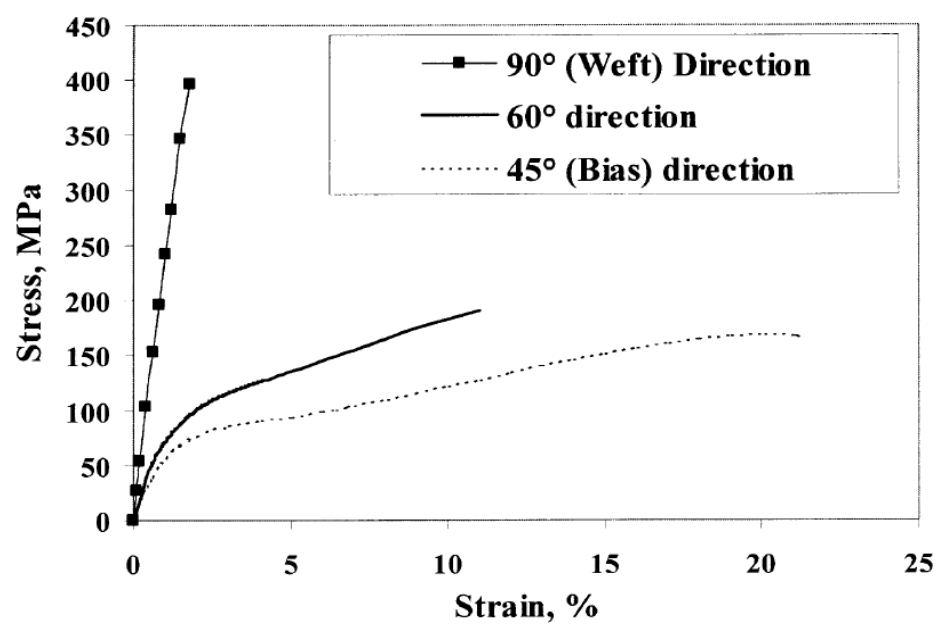

Figure 2. Static stress strain response [19].

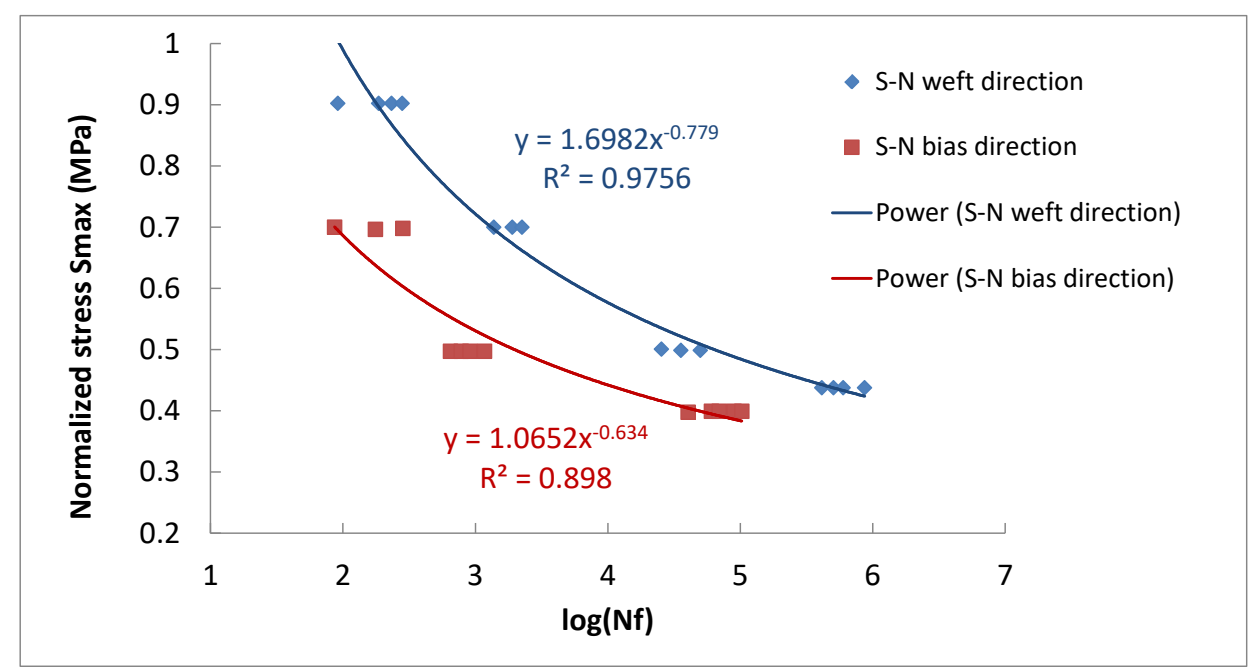

Figure 3. S-N test data of (90/0) and (45/-45) coupons [19] and fitting curves.

An Abaqus FE model of the (90/0) fabric specimen was developed and is presented in Fig. 4 for fatigue damage prediction. The model consists of 60,000 solid elements (C3D8) with the same glass/R420 material as used in the test [19]. The specimen is loaded in tension-tension fatigue at one end while the other end is fixed. The tested S-N data of the (90/0) and (45/-45) specimens are fitted in the exponential form: $y=\alpha_{i}(x)^{-\beta_{i}}$ with $\mathrm{x}=\log N$ as shown in Fig. 3. The fatigue analysis consists of two loading steps: the first static step is to load the specimen to the designed maximum stress, e.g. $50 \%$ or $70 \%$ of the ultimate static strength and predict the corresponding static damage prior to cycling, followed by a fatigue step to perform the material degradation at incremental loading cycles.

Fig. 5 depicts the fatigue damage prediction of the (90/0) E-glass/R420 fabric specimen under axial-tension cyclic loading at $50 \%$ and $70 \%$ of ultimate static strength (UTS). Fiber tow failure predicted for the (90/0) coupon is shown in red in Fig. 5. The estimated number of cycles to failure of the (90/0) specimen is about 25,000 cycles for 
the $50 \%$ UTS $\left(S_{\max } / S_{\text {static }}=0.5\right)$ and 1,352 cycles for the $70 \%$ UTS $\left(S_{\max } / S_{\text {static }}=0.7\right)$. They all agree well with the measured fatigue cycles of the (90/0) coupons from tests at the corresponding stress levels.

The predicted damage index for the (45/-45) fabric coupon at 50\% UTS is given in Fig. 6 for the +45 tow, -45 tow and matrix. It is shown that the matrix fatigue damage is initiated at the early stage, followed by the development of fiber tow failure along the $45^{\circ}$ and $-45^{0}$ direction. The estimated fatigue life of the (45/-45) coupon is 844 cycles, which is within the tested cycle range of $649-1176$ cycles as reported in Reference [19]. Fig. 7 plots the evolution of the shear stiffness of the (45/-45) coupon against number of cycles. A sudden shear stiffness drop occurs at about 700 cycles. Due to the additional load shared by the fiber tows, accelerate fatigue damage is accumulated and the final failure occurs after additional 150 cycles.

Using the extracted S-N model parameters from the (90/0) and (45/-45) coupons, the fatigue damage and fatigue life prediction was performed for the (30/-60) specimen at 50\% UTS. Fig. 8 shows the fatigue cycle prediction of the (30/-60) coupon along with its comparison with the testing results by Pandita et al. [19]. Fatigue damage distribution associated with the shear and fiber tow failure modes are shown in Fig. 8. The estimated number of fatigue cycles for the (30/-60) coupon is 2,423 which correlates well with the test data in the range of 1,767 to 4,976 cycles.

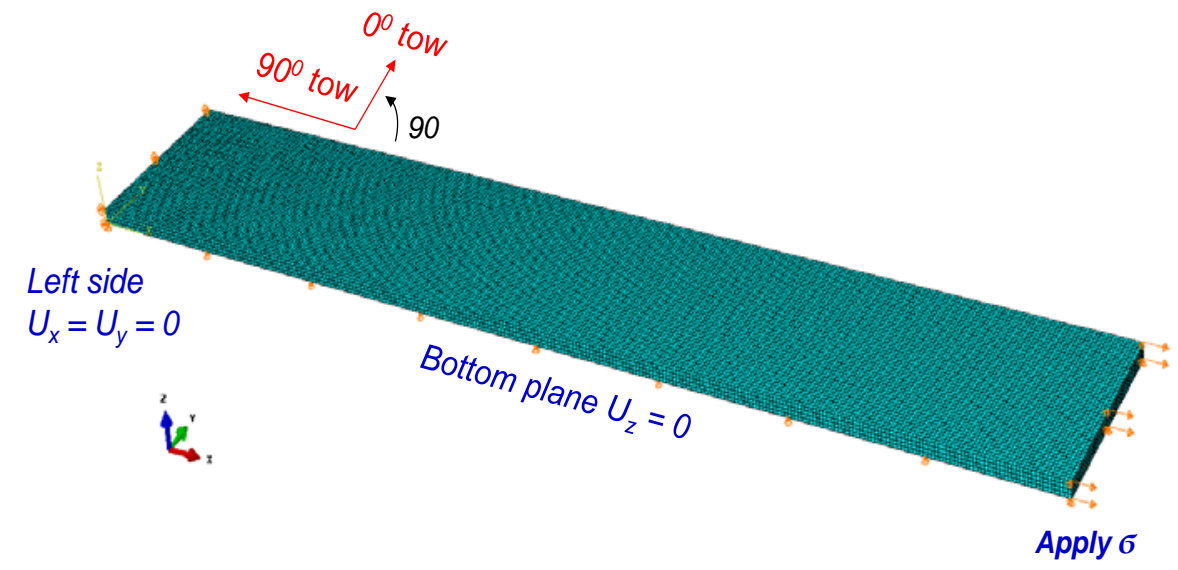

Figure 4. FEM model for E-glass/R420 plain weave of [90/0] layup.

$$
S_{\max }=200 \mathrm{MPa}\left(S_{\max } / S_{\text {static }}=0.5\right)
$$

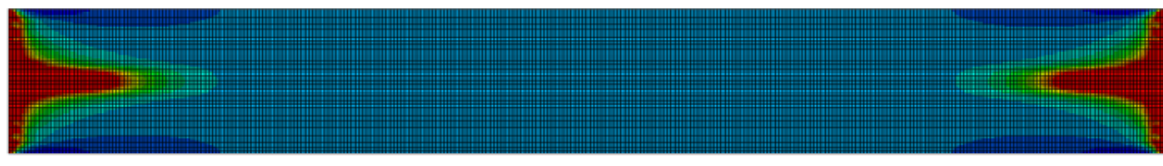

Experimental testing: 25375 - 50039 cycles

Predicted fatigue cycle: 25000 cycles
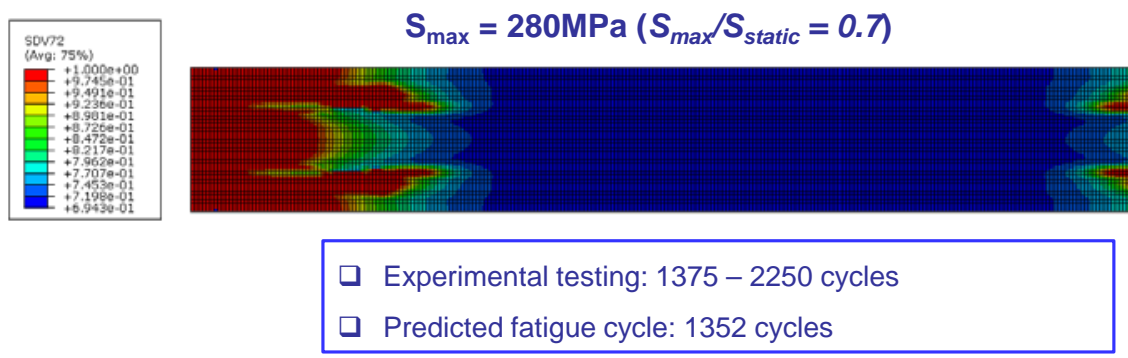

Figure 5. Fatigue damage (in red) and number of cycles to failure prediction of the (90/0) specimens in comparison with testing results. 


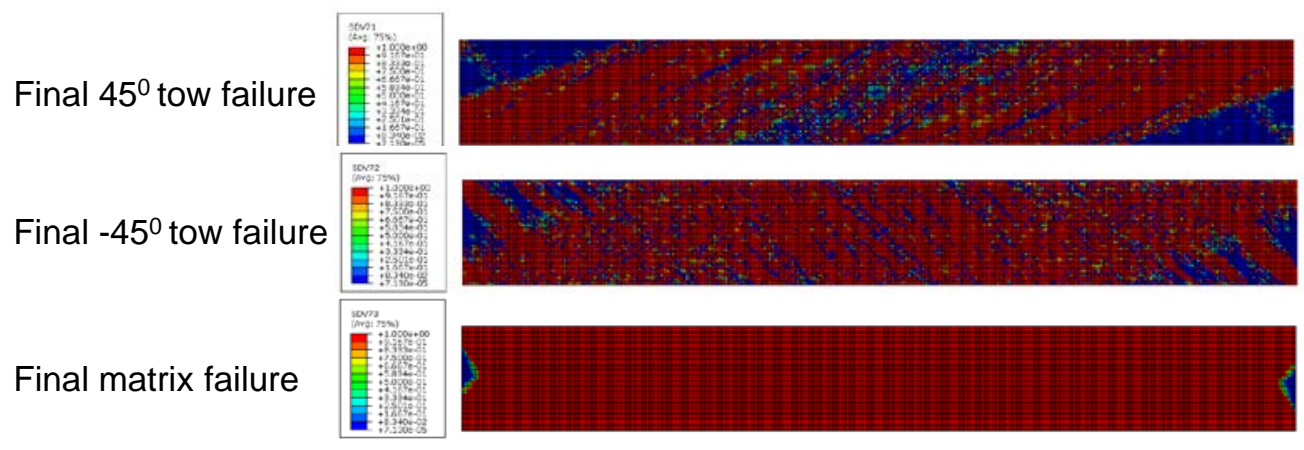

- Predicted fatigue cycle: 844 cycles

Experimental testing: $649-1176$ cycles

Figure 6. Fatigue damage (in red) and number of cycles to failure prediction of the (45/-45) specimens in comparison with testing results.

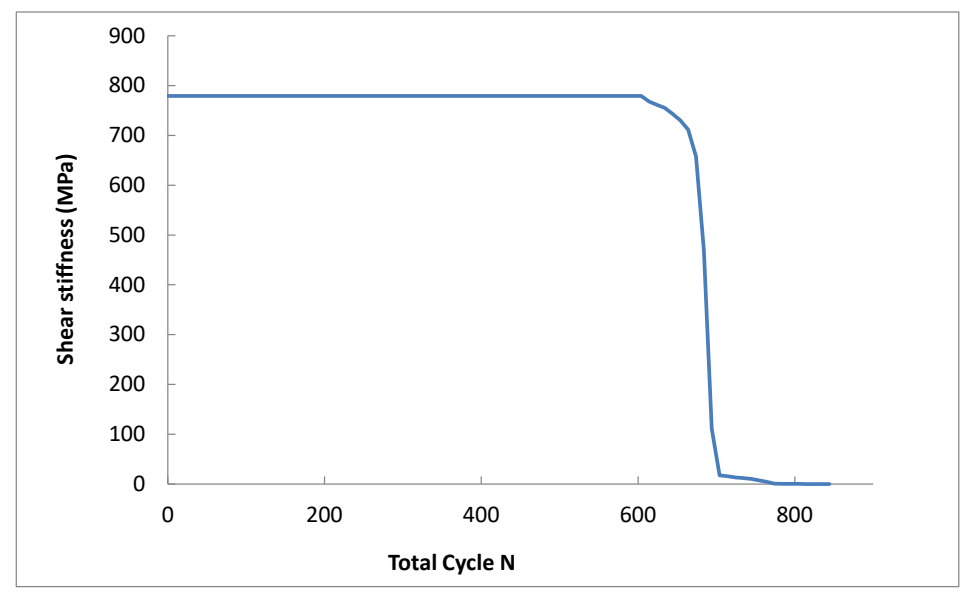

Figure 7. Shear stiffness reduction of the (45/-45) specimens at increasing cycle.

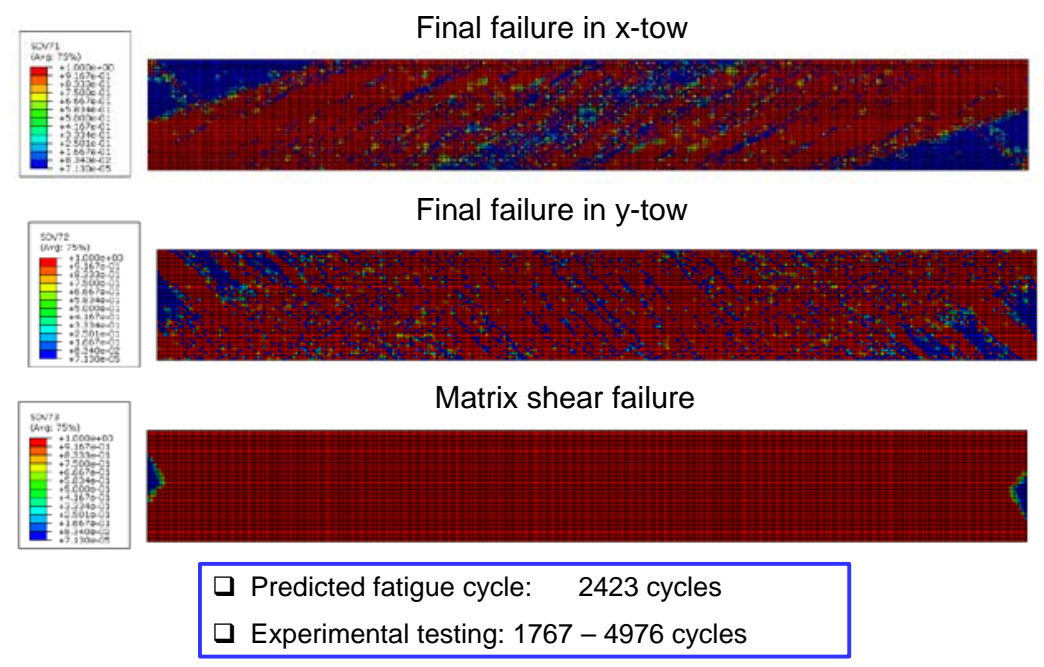

Figure 8. Fatigue damage (in red) and number of cycles to failure prediction of the (30/-60) specimens in comparison with testing results.

American Institute of Aeronautics and Astronautics 


\section{Conclusions}

A 3D progressive fatigue damage model has been developed to predict the failure progression in the $\mathrm{X}$-tow, $\mathrm{Y}$ tow, and matrix phase. The maximum stress criteria along with the use of cycle dependent strength parameters have been applied to predict the damage initiation and fatigue damage accumulation. The matrix dominant nonlinear shear behavior has been characterized using a curve-fit model based on the static test data of the woven fabric coupon of (+45/-45) layup. Using the fatigue model parameters extracted from the S-N data of the coupons of (90/0) and (+45/-45) layups, the developed fatigue damage prediction model has shown its capability to perform damage progression and life prediction of specimens of other layups. The predicted results have been verified against the available testing data of E-glass/R420 coupons with (90/0), (45/-45) and (30/60) layups reported by Pandita et al. [19] in the literature. Favorable agreements between the experiment results and simulation have been achieved. Future study will be performed for fatigue life prediction of woven fabric composites of other configurations such as a bonded joint and a composite panel with a pre-notch.

\section{References}

1. Tang, X.D., Whitcomb, J.D., "Progressive Failure Behaviors of 2D Woven Composites", Journal of Composite Materials, Vol. 37, No. 14, 2003, pp. 1239 - 1259.

2. Key, C.T., Schumacher, S.C., Hansen, A.C, "Progressive failure modeling of woven fabric composite materials using multicontinuum theory”, Composites Part B: Engineering, Vol. 38, No. 2, 2007, pp. 247-257.

3. Koumpias, A. S., Tserpes, K. I. and Pantelakis, S., "Progressive damage modelling of 3D fully interlaced woven composite materials”, Fatigue \& Fracture of Engineering Materials \& Structures, 37, 2014, pp. 696-706.

4. Pham, D.C., Sun, X.S., "Experimental and computational studies on progressive failure analysis of notched cross-ply CFRP composite”, International Journal of Computational Materials Science and Engineering, Vol. 1, No. 3, 2012.

5. Warren, K.C., Lopez-Anido, R.A., Vel, S.S. and Bayraktar, H.H., "Progressive failure analysis of three-dimensional woven carbon composites in single-bolt, double-shear bearing”, Composites Part B: Engineering, Vol. 84, 2016, pp. 266-276.

6. Iannucci, L. "Progressive failure modelling of woven carbon composite under impact", International Journal of Impact Engineering, Vol. 32, No. 6, 2006, pp.1013-1043.

7. Pham, D.C., Narayanaswamy S., “An effective modeling strategy for drop test analysis of composite curved beam”, 56th AIAA/ASCE/AHS/ASC Structures, Structural Dynamics, and Materials Conference, AIAA SciTech Forum 2015.

8. Pham, D.C., Narayanaswamy S, “An Optimization Tool for Impact Analysis of Composite Structures", Procedia Engineering, Vol. 75, 2014, pp. 3-8.

9. Nikishkov, Y., Makeev, A., Seon, G., "Progressive fatigue damage simulation method for composites”. International Journal of Fatigue. Vol. 48, 2013, pp. 266-279.

10. Shokrieh, M.M., and Lessard, L.B., "Progressive fatigue damage modeling of composite materials, Part I: Modeling”, Journal of Composite Materials, Vol. 34, No. 13, 2000, pp. 1056-1080.

11. Montesano, J., Selezneva, M., Levesque M. and Fawaz, Z. "Modeling fatigue damage evolution in polymer matrix composite structures and validation using in-situ digital image correlation”, Composite Structures, Vol. 125, 2015, pp. 354-361.

12. Cui, X.D., Fang, E., and Lua, J., "An Integrated Crack Initiation and Propagation Module for Fatigue Damage Prediction of Composite Structures", 58th AIAA/ASCE/AHS/ASC Structures, Structural Dynamics, and Materials Conference, AIAA SciTech Forum, 2017

13. Xiao, J., Fang, E., Lua, J., Li, R. and Zhang, D. "A Multiscale Fatigue Damage Prediction for Notched Composite Components", 58th AIAA/ASCE/AHS/ASC Structures, Structural Dynamics, and Materials Conference, AIAA SciTech Forum 2017

14. Hoos, K., Iarve, E.V., Braginsky, M., Zhou, E. and Mollenhauer, D.H., "Progressive Failure Simulation in Laminated Composites under Fatigue Loading by Using Discrete Damage Modeling”. In 57th AIAA/ASCE/AHS/ASC Structures, Structural Dynamics, and Materials Conference, San Diego, California. 4-8 January, 2016. pp. 0726.

15. May M and Hallett SR. "A combined model for initiation and propagation of damage under fatigue loading for cohesive interface elements”. Compos Part A, Vol. 41, 2010, pp. 1787-1796.

16. May M and Hallett SR. "An advanced model for initiation and propagation of damage under fatigue loading - part I: Model formulation”. Composite Structures. Vol. 93, 2011, pp. 2340-2349.

17. Huang, Z.M., "Fatigue life prediction of a woven fabric composite subjected to biaxial cyclic loads", Composites Part A: Applied Science and Manufacturing, Vol. 33, No. 2, 2002, pp. 253-266.

18. Xu, J., Lomov, S.V., Verpoest, I., Daggumati, S., Paepegem, W.V and Degrieck, J., “A progressive damage model of textile composites on meso-scale using finite element method: Fatigue damage analysis”, Computers \& Structures, Vol. 152, 2015, pp. 96-112.

19. Pandita, S. D., Huysmans, G., Wevers, M. and Verpoest, I., “Tensile fatigue behavior of glass plain-weave fabric composites in on- and off-axis directions”, Composite Part A, Vol 32, pp 1533-1539, 2001. 
20. Hashin, Z. and Rotem, A. “A fatigue failure criterion for fiber reinforced materials”. Journal of Composite Materials, Vol. 7, pp. 448-64, 1973.

21. Miner M. “Cumulative damage in fatigue”. Journal of Applied Mechanics, Vol. 12, 1945, pp. 159-64.

22. Camanho, P.P., Davila, C.G., Pinho, S.T., Iannucci, L., Robinson, P., "Prediction of in situ strengths and matrix cracking in composites under transverse tension and inplane shear”, Composites Part A, Vol. 37, 2006, pp.165-76. 